\title{
Computer-Aided Drug Discovery in Plant Pathology
}

\author{
Gnanendra Shanmugam and Junhyun Jeon* \\ Department of Biotechnology, College of Life and Applied Sciences, Yeungnam University, Gyeongsan, Gyeongbuk \\ 38541, Korea
}

(Received on April 12, 2017; Revised on September 6, 2017; Accepted on September 6, 2017)

Control of plant diseases is largely dependent on use of agrochemicals. However, there are widening gaps between our knowledge on plant diseases gained from genetic/mechanistic studies and rapid translation of the knowledge into target-oriented development of effective agrochemicals. Here we propose that the time is ripe for computer-aided drug discovery/design (CADD) in molecular plant pathology. CADD has played a pivotal role in development of medically important molecules over the last three decades. Now, explosive increase in information on genome sequences and three dimensional structures of biological molecules, in combination with advances in computational and informational technologies, opens up exciting possibilities for application of CADD in discovery and development of agrochemicals. In this review, we outline two categories of the drug discovery strategies: structureand ligand-based CADD, and relevant computational approaches that are being employed in modern drug discovery. In order to help readers to dive into CADD, we explain concepts of homology modelling, molecular docking, virtual screening, and de novo ligand design in structure-based CADD, and pharmacophore modelling, ligand-based virtual screening, quantitative structure activity relationship modelling and de novo ligand design for ligand-based CADD. We also provide the important resources available to carry out CADD. Finally, we present a case study showing how CADD approach can be implemented in reality for identification of po-

\footnotetext{
*Corresponding author.

Phone) +82-53-810-3030, FAX) +82-53-810-4769

E-mail)jjeon@yu.ac.kr

(c) This is an Open Access article distributed under the terms of the Creative Commons Attribution Non-Commercial License (http:// creativecommons.org/licenses/by-nc/4.0) which permits unrestricted noncommercial use, distribution, and reproduction in any medium, provided the original work is properly cited.
}

Articles can be freely viewed online at www.ppjonline.org. tent chemical compounds against the important plant pathogens, Pseudomonas syringae and Colletotrichum gloeosporioides.

Keywords : computer-aided drug discovery, agrochemicals, structure-based CADD, ligand-based CADD, control of plant disease

Handling Associate Editor : Seo, Young-Su

Control of plant diseases is one of the challenges that humanity as a whole faces in ensuring that current and future populations are adequately fed (Strange and Scott, 2005). To address such a challenge, a number of different approaches have been used separately or in combination to prevent or control the plant diseases. Growers, however, often rely heavily on pesticides and other agrochemicals, although great efforts have been put into development and deployment of crop plants that are resistant to plant pathogen(s) (Chandler et al., 2011). Over the last few decades, molecular plant pathologists have strived to pinpoint molecular attributes of pathogens that confer ability to cause disease on their host plant, hoping to provide targets for molecular breeding and discovery of agrochemicals (Boyd et al., 2013; Hentschel et al., 2000).

During the last two decades, the ccomputer aided drug designing (CADD) has become a critical part of the development of novel drugs in pharmaceutical industries (Adam, 2005; Taylor, 2015). However, CADD has not been extensively used toward design/development of chemicals that can control diseases of crop plants. Only a handful of studies have been conducted using CADD in plant pathology (Kandakatla and Ramakrishnan, 2014; Pathak et al., 2016; Soundararajan et al., 2011; Zhou et al., 2015). For example, Yang et al. (2002) successfully screened the novel 2-heteroaryl-4-chromanones with antifungal activity against the rice blast fungus using CADD approach. Xue et al. (2014) 
modeled the structure of Tps1 (trehalose-6-phosphate synthase 1) as potential drug target in Magnaporthe oryzae and reported the potential chemical inhibitor by screening 400,000 chemical compounds from Molecular Libraries Small Molecule Repository. Liu et al. (2012) reported the modelled structures of Gnt-R like regulators from Xanthomonas axonopodis pv. Citri (Xac) and its binding sites. The homology modeling of $14 \alpha$-demethylase from Ustilago maydis and the screening of synthetic XF-113 and ZST4 fungicide lead compounds as novel $14 \alpha$-demethylase inhibitors were reported by Han et al (2010). Dehury et al. (2013) reported the modelled structure of race-specific bacterial blight disease resistance protein (xa5) against Xanthomonas oryzae. Doucet-Personeni et al. (2001) reported the rational design of acetylcholinesterase inhibitors (insecticides) by combing the common features of organophosphate and carbamate compounds (tacrine and trifluoromethyl ketones). In another work, structures of hydacidin and hydantocidin (pro-herbicides) were combined to design the hybrid adenylosuccinate synthetase inhibitors as a novel herbicides by Hanessian et al (1999). The identification of indenone and salicylamide analogue as trihydroxy naphthalene reductase and scytalone dehydratase respectively is the most prominent example of CADD ap-

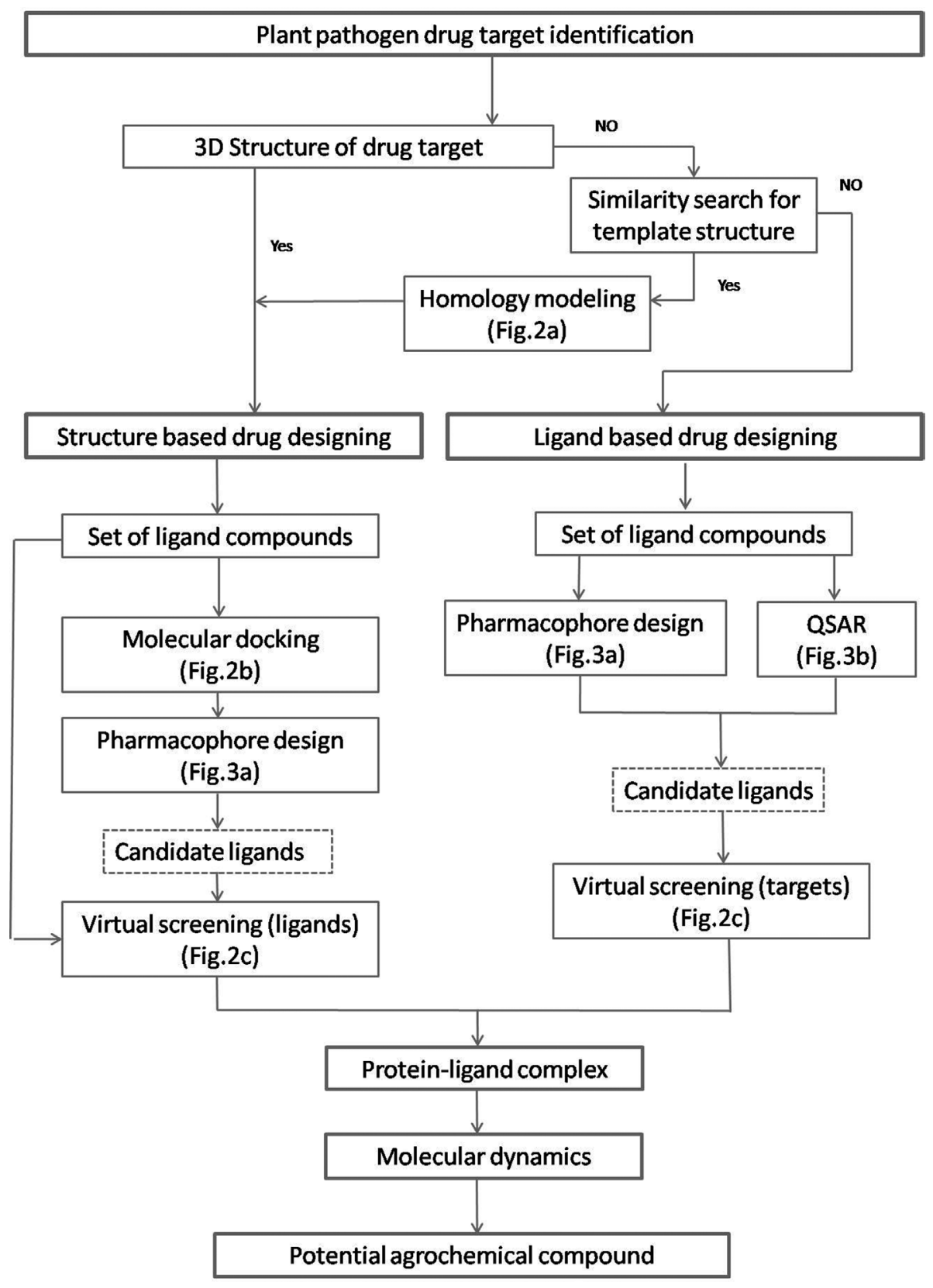

Fig. 1. A schematic diagram of a typical computer aided drug discovery process for agrochemicals, starting from target identification to hit-to-lead exploration. A general pipeline for the structure based drug designing (SBDD) and ligand based drug designing (LBDD) approaches was depicted in work flow format. Important concepts explained in more detail in other figures were indicated in parentheses. 
proach in the design of new agrochemicals (Walter, 2002).

Despite such examples, use of CADD in plant pathology has been significantly lagging behind. This was mainly due to 1) lack of information and training on CADD for researchers in plant pathology-related disciplines and 2) insufficiency of data for accurate modelling and simulation. Recent advances in genomics and bioinformatics, together with explosive increase in genome sequence information, enabled researchers to rapidly identify and test large number of candidate genes and their translational products that are responsible for pathogenesis of plant pathogens (Cairns et al., 2016; Imam et al., 2016;). Some of these candidates include proteins that are secreted into apoplasm or cytoplasm of plants to subvert defense mechanisms and to manipulate metabolism of host plants in favor of pathogens (Deslandes and Rivas, 2012; Franceschetti et al., 2017). In addition, data regarding three-dimensional (3D) structure of such virulence/pathogenicity proteins based on NMR or X-ray crystallography are rapidly increasing (currently PDB holds 128,962 biological macromolecular structures) (Rost and Sander, 1996; Schwede, 2013).

With burgeoning information and technologies, here we propose that the time is ripe for CADD in molecular plant pathology. Even with a personal computer connected to the internet, CADD can be carried out for efficient development of new agrochemicals having novel targets. From this perspective, here we outline basic concepts and overview of CADD (Fig. 1), without going into too much detail, to encourage and guide molecular plant pathologists who want to see translation of their works into chemical control of the diseases. To that end, we provide list of resources that are useful and currently available in drug designing pipeline (Table 1). Last but not least, we provide a case study of CADD targeting pathogenicity factors from selected plant pathogens for demonstration purpose. For those who are complete novice to CADD, terminologies that are going to be used throughout this review are listed and explained in Table 2.

\section{What is CADD and Why Do We Want to Use It?}

Drugs are the chemical compounds/molecules that can either activate or inhibit biomolecules, which in turn, promote health and survivability of human. In ancient times,

Table 1. List of the important resources used in CADD

\begin{tabular}{|c|c|c|}
\hline Application (database/tool) & Resource & Availability (Commercial/Free) \\
\hline \multirow[t]{3}{*}{ Chemical compound database } & Pubchem & Free access \\
\hline & DrugBank & Free access \\
\hline & Maybridge & Limited free access \\
\hline \multirow[t]{3}{*}{ Structure drawing / editing tool } & ACD Chemsketch & Academic free access \\
\hline & Marvin Sketch & Academic free access \\
\hline & JChem & Academic free access \\
\hline \multirow[t]{3}{*}{ Visualization tool } & Rasmol & Free access \\
\hline & Jmol & Free access \\
\hline & Pymol & Academic free access \\
\hline \multirow[t]{2}{*}{ Compound property prediction } & Molinspiration & Free access \\
\hline & Molsoft & Free access \\
\hline \multirow[t]{3}{*}{ Protein modelling tools } & Modeller & Free access \\
\hline & SwissPDBViewer & Free access \\
\hline & Swissmodel & Free access \\
\hline File format converter tool & OpenBabel & Academic free access \\
\hline \multirow[t]{4}{*}{ Virtual screening and docking softwares } & FlexX & Commercial \\
\hline & AutoDock & Academic free access \\
\hline & GLIDE & Commercial \\
\hline & PyRX & Academic free access \\
\hline \multirow[t]{3}{*}{ Pharmacophore softwares } & HipHop & Commercial \\
\hline & HypoGen & Commercial \\
\hline & PHASE & Commercial \\
\hline QSAR tool & Easy QSAR & Academic free access \\
\hline Molecular dynamics software & Desmond & Academic free access \\
\hline
\end{tabular}


Table 2. Terminology in CADD

\begin{tabular}{|c|c|}
\hline Terms & Definition/Description \\
\hline Drug (or) ligand & $\begin{array}{l}\text { The small chemical compound that can bind to protein or enzyme and can treat the disease } \\
\text { or a small chemical compound that binds to macromolecules as signals to start (catalyse) } \\
\text { the reaction. }\end{array}$ \\
\hline Receptor (or) Target & $\begin{array}{l}\text { A biological molecule (mostly macromolecules such as protein and DNA) that can receive a } \\
\text { chemical signal (ligand) to catalyse a reaction or function. }\end{array}$ \\
\hline Drug designing & $\begin{array}{l}\text { A process of finding a small chemical compound that can bind to macromolecules and } \\
\text { works as a drug. }\end{array}$ \\
\hline Chemo informatics & $\begin{array}{l}\text { A branch of science that deals with the study of small chemical compounds information } \\
\text { such as properties, structures and functions. }\end{array}$ \\
\hline SBDD (Structure based drug designing) & $\begin{array}{l}\text { A drug designing approach that works only with availability of protein (receptor) 3D struc- } \\
\text { ture. In this process the search for small chemical compounds are carried. }\end{array}$ \\
\hline LBDD (Ligand based drug designing) & $\begin{array}{l}\text { A drug designing approach that works on the availability of small chemical compound } \\
\text { (ligand) structure. }\end{array}$ \\
\hline Clefts/Cavities/Binding pockets & $\begin{array}{l}\text { The space or gap regions in the protein structure. These regions are essential for the binding } \\
\text { of small chemical compounds that acts as signal or drug molecule. }\end{array}$ \\
\hline Homology modelling & $\begin{array}{l}\text { Building the 3D structure of protein (target) based on the availability of experimentally (X- } \\
\text { ray or NMR) derived 3D structures of another related (template) protein that shares the } \\
\text { similarity. }\end{array}$ \\
\hline Docking & This is a process of analysing the binding interactions of ligand and receptor molecules. \\
\hline Virtual screening & $\begin{array}{l}\text { A computational process in which a large number of ligand (small) molecules are screened } \\
\text { (analysed) to possess the best docking interactions with the receptor molecule. }\end{array}$ \\
\hline Ligand conformation & The orientation of the ligand molecule bound in the receptor binding site. \\
\hline Pharmacophore & $\begin{array}{l}\text { The 3D representation of chemical features such as H-bond acceptors, H-bond donors, and } \\
\text { hydrophobic regions possessed by the ligand compound or receptor binding site. }\end{array}$ \\
\hline QSAR & $\begin{array}{l}\text { Quantitative structure activity relationship: a mathematical model used to define the rela- } \\
\text { tionship between the physico-chemical properties and biological activity of compounds. }\end{array}$ \\
\hline
\end{tabular}

the usage of plant extracts has been the source of treatment for various disease and many people believed that plants might possess protective means against infections disease as it continues to survive with high bacterial density in an environment (Al-Hussaini and Mahasneh, 2009; Cos et al., 2006). In late $1800 \mathrm{~s}$, with the key developments in the basic sciences such as identification of bacteria and virus, in-depth knowledge on the chemical substance in the plants has become essential in the treatment of disease (Katiyar et al., 2012). Further advancements in the technologies such as X-ray crystallography, NMR spectroscopy and structural genomics have improved the determination of the exact chemical composition of the compounds and selection of potential drug targets (Hughes et al., 2011; Weigelt, 2010). This gradual advancement in understanding the molecular basis of compound structure and drug targets has channelized the drug discovery pipeline with optimization and testing steps (Duffy et al., 2012). Such traditional drug discovery process includes screening, separation, characterization, and synthesis of the molecules with desired therapeutic activity on cultured cells or animals.

Among the steps in the traditional drug discovery pipeline, screening of large number molecules for the desired activity was one of the major bottlenecks. Although this brute force approach has the advantage in that it does not require prior knowledge of molecules, chances of finding novel drugs are generally very low (low hit rate), making it time-consuming and cost-ineffective (Kapetanovic, 2008; Sliwoski et al., 2013). This is the point at which CADD comes into play. CADD can be defined as the design/discovery of molecules that has strong binding affinity to biomolecular target in a computer-modelingdependent manner. The fundamental goal of CADD is to predict which molecules among many will bind to a target and if so how strongly they will, using knowledge and information on molecular mechanics and dynamics. The CADD serves as an alternative strategy to experimental screening techniques, greatly reducing the cost, time, and workload for drug development. For example, researchers can significantly decrease the number of compounds that 
need to be screened without compromising lead discovery, because CADD allows them to skip many compounds that are predicted to be inactive (virtual screening). In addition, CADD can be used for other stages of drug discovery including hit-to-lead optimization of affinity and selectivity. There are two major types of CADD: structure-based drug design (SBDD) and ligand-based drug design (LBDD). We will briefly introduce key concepts of each type of CADD in the following section. In general, the availability of $3 \mathrm{D}$ structure information of targets (often proteins) is the key to determining which approaches should be taken.

\section{Target Identification}

Target identification is the foremost step in drug discovery pipeline. The properties such as essentiality (role in pathophysiology), specificity (most specific to particular disease/ host), druggability (function modification through the bind-

Table 3. List of few reported potential drug targets from plant pathogens

\begin{tabular}{|c|c|c|c|}
\hline Drug target & Function & Target pathogen & Reference \\
\hline $\begin{array}{l}\text { Mur Enzymes } \\
\text { Pectate lyase }\end{array}$ & $\begin{array}{l}\text { Peptidoglycan synthesis } \\
\text { Cell wall degrading enzymes }\end{array}$ & $\begin{array}{l}\text { Bacterial pathogens } \\
\text { Bacterial and fungal pathogens }\end{array}$ & $\begin{array}{l}\text { El Zoeiby et al., } 2003 \\
\text { Herron et al., } 2000\end{array}$ \\
\hline $\begin{array}{l}\text { Ergosterol biosynthesis } \\
\text { pathway }\end{array}$ & $\begin{array}{l}\text { Generation of a major constituent of } \\
\text { the plasma membrane }\end{array}$ & Fungal pathogens & Siegel, 1981 \\
\hline Lanosterol $14 \alpha$-demethylase & Steroid biosynthesis & Fungal pathogens & Sagatova et al., 2015 \\
\hline$\beta$-tubulin (TUB2) & Microtubule assembly & Fungal pathogens & Wride et al., 2014 \\
\hline Threonyl-tRNA synthetases & Protein translation and cell viability & Phytophthora sojae & Gao et al., 2012 \\
\hline Dihydrofolate reductase & Nucleotide precursor biosynthesis & $\begin{array}{l}\text { Phytophthora spp., Ustilago spp., } \\
\text { Puccinia spp. }\end{array}$ & Jain et al., 2017 \\
\hline $\begin{array}{l}\text { Trehalose-6-phosphate } \\
\text { synthase } 1 \text { (Tps-1) }\end{array}$ & $\begin{array}{l}\text { Trehalose synthesis - energy and } \\
\text { carbon storage }\end{array}$ & Magnaporthe oryzae & Xue et al., 2014 \\
\hline Asparagine synthase (Asn1p) & Pathogenecity & $\begin{array}{l}\text { Magnaporthe grisea } \\
\text { Botrytis cinerea } \\
\text { Fusarium graminearum } \\
\text { Colletotrichum spp. } \\
\text { Ustilago maydis }\end{array}$ & $\begin{array}{l}\text { Ramakrishnan et al., } 2016 \\
\text { Dunn et al., } 2009\end{array}$ \\
\hline Isocitrate lyase & Virulence & $\begin{array}{l}\text { Leptosphaeria maculans } \\
\text { Magnaporthe grisea } \\
\text { Stagonospora nodorum } \\
\text { Colletotrichum lagenarium } \\
\text { Rhodococcus fascians } \\
\text { Xanthomonas campestris }\end{array}$ & $\begin{array}{l}\text { Dunn et al., } 2009 \\
\text { Dean et al., } 2012\end{array}$ \\
\hline $\begin{array}{l}\text { MAPK signalling and calcium } \\
\text { signalling pathways }\end{array}$ & $\begin{array}{l}\text { Invasive hyphal growth, Morpho- } \\
\text { genesis, Biogenesis of the cell } \\
\text { wall, Dimorphism, and the stress } \\
\text { response }\end{array}$ & $\begin{array}{l}\text { Magnaporthe grisea } \\
\text { Botrytis cinerea } \\
\text { Fusarium oxysporum } \\
\text { Blumeria graminis } \\
\text { Colletotrichum spp. } \\
\text { Ustilago maydis } \\
\text { Melampsora lini }\end{array}$ & $\begin{array}{l}\text { Dean et al., } 2012 \\
\text { Chen and Dickman, } 2004 \\
\text { Takano et al., } 2000\end{array}$ \\
\hline Type III secretion system & Pathogenicity & $\begin{array}{l}\text { Pseudomonas syringae } \\
\text { Ralstonia solanacearum } \\
\text { Xanthomonas axonopodis }\end{array}$ & $\begin{array}{l}\text { Mansfield et al., } 2012 \\
\text { Jovanovic et al., } 2011 \\
\text { Boucher et al., } 1985\end{array}$ \\
\hline Type IV secretion system & Transport into the host & Agrobacterium tumefaciens & Pitzschke and Hirt, 2010 \\
\hline Rpf gene products & Regulation of pathogenicity factors & $\begin{array}{l}\text { Xanthomonas oryzae } \\
\text { Xanthomonas campestris } \\
\text { Xanthomonas axonopodis }\end{array}$ & $\begin{array}{l}\text { Mole et al., } 2007 \\
\text { Boch and Bonas, } 2010 \\
\text { Mansfield et al., } 2012\end{array}$ \\
\hline $\mathrm{HrpN}$ & Pathogenicity & $\begin{array}{l}\text { Erwinia amylovora } \\
\text { Ralstonia solanacearum }\end{array}$ & $\begin{array}{l}\text { Bocsanczy et al., } 2008 \\
\text { Boucher et al., } 1985\end{array}$ \\
\hline
\end{tabular}


ing of small molecules) and selectivity (well defined active site allowing differential binding of small molecules) of a macromolecule are considered as important features for the selection of ideal target. The selection and choice of ideal macromolecule as drug targets by considering the essential criterion will influence the outcome of the drug discovery process (Chandra, 2011). Based on the above mentioned criteria, certain macromolecules that could serve as potential drug targets in plant pathogens are summarized in Table 3.

\section{Structure-Based Drug Design/Discovery (SBDD)}

Availability of 3D structure and prior knowledge on biological function(s) of target protein are pre-requisites for SBDD approach. Based on the structure of the target protein, SBDD allows design of candidate drugs that are predicted to bind to the target with high affinity and selectivity (Kalyaanamoorthy and Chen, 2011). Assumption that underlies and justifies SBDD approach is that a molecule's potential to have desired biological effects for a specific protein relies on its degree of ability to interact with binding sites on that protein.

Homology modelling. If there is no 3D structure information of the target, it may be possible to create homology model (this is called homology modelling) based on primary sequence similarity of the target to homologous proteins, of which 3D structure is empirically known (Fig. 2A). The 3D structure, whether it is experimental or predicted structure, of target protein provides information about chemical environment of the active site(s), enabling researchers to identify ligand(s) (drug or agrochemicals) that can bind to the active site with high affinity and selectivity. One thing that researchers should bear in mind is that, since homology modelling builds the 3D structures of proteins based on template sequences, the accuracy of the built model depends on the choice of template, alignment accuracy and refinement of the model (Rost, 1999). Generally, the models built with the templates exhibiting over $70 \%$ identities are considered to be accurate enough for drug discovery applications (Cavasotto and Phatak, 2009).

Molecular docking. Once the model providing chemical environment of active sites is built, protein-ligand interactions can be explored through molecular docking, a method that predicts energetically stable orientation of ligand when it is bound to target protein (Fig. 2B). Degree of stability of interaction between molecules is the key factor to determining biological consequences of the interaction (Durrant and McCammon, 2010). Molecular docking reports two important information: 1) correct conformation of a ligandtarget (or ligand-receptor) complex and 2) its binding affinity which represents an approximation of the binding free energy (mathematical methods called scoring functions are used to estimate binding interaction of the protein-ligand complex). More than 30 molecular docking programs are currently available (Huang and Zou, 2010; Ferreira et al., 2015).

Structure-based virtual screening (SBVS). The search for new chemical compounds as lead molecules is a critical step during the process of drug discovery. Once the target is selected, the small molecules database are selected for virtual screening and their binding interactions with the selected drug target are explored. The top ranked compounds with desired binding interactions are selected as lead compounds for the further steps. Virtual screening is a computational method that evaluates large libraries of compounds and subsequently identifies putative hits (leads) through comparison of 3D structures of ligands with the putative active site of the target (Fig. 2C). In structure-based virtual screening, affinity of the ligand to the target protein is estimated using molecular docking followed by application of scoring function. Virtual screening is extensively automated and fast method in identifying the candidate compounds from a large dataset based on their rank in docking interactions (McInnes, 2007). This allows researchers to focus their resources and efforts on testing compounds likely to have desired activity.

De novo ligand design (DnLD). Using 3D structure information of the target, ligand can be designed de novo. DnLD can be carried out in both structure-based and ligand-based drug design. These de novo methods are usually carried with the placement of pseudo-molecular probe molecule and then addition of functional groups to satisfy the spatial constraints of target binding site. Also, the molecule will be grown fragment by fragment to occupy the active site of target molecules. Please see de novo ligand design in the next section.

\section{Ligand-Based Drug Designing (LBDD)}

In many cases, 3D structure of target protein or its homolog is not available for SBDD approach. This is true in particular for proteins that are present in cell surface or membrane due to their inherent difficulties in protein crystallization. In some cases, the use of unreliable homologous proteins (for example, low sequence identity) for homology model- 

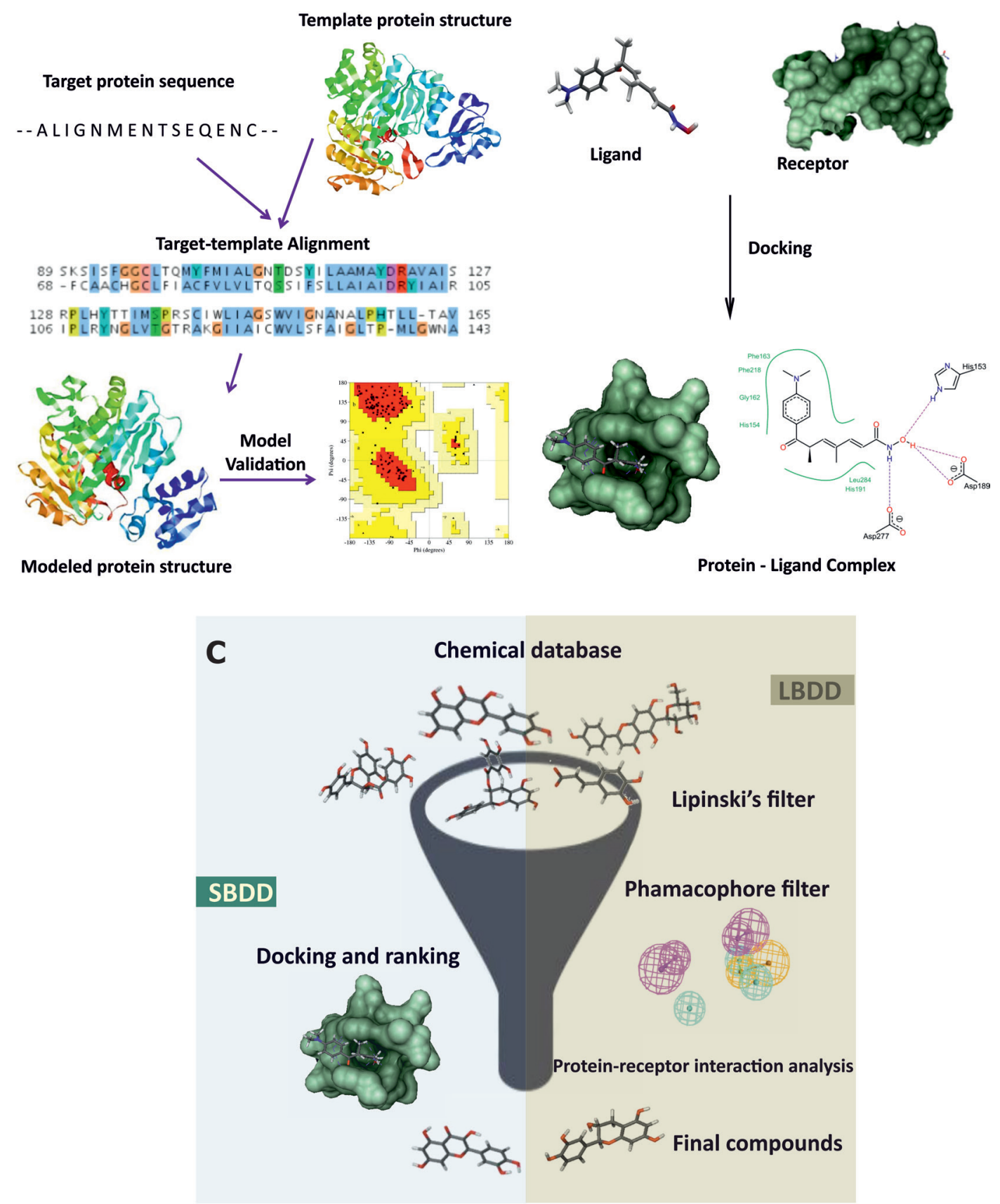

Fig. 2. The most prominent steps in the SBDD and LBDD approaches. (A) Homology modelling and validation. The target-template alignment leads to the modelling of 3D structure of target protein and this model is validated by Ramachandran plot (using PROCHECK). (B) Docking process. The small molecule/ligand (chemical compound, stick representation) and the macromolecule/receptor (protein, molecular surface representation) are allowed to interact with each other (using docking software). (C) The general outline of virtual screening in SBDD and LBDD approach. In SBDD, large numbers of ligand are screened against the known receptor. In LBDD, the chemical entities of single ligand is used to screen hit compounds and/or screened against various protein targets of interest.

ling can result in high rate of false positive hits. In such situations, researcher can take LBDD. LBDD relies on knowledge of structural and chemical characteristics that molecules must have for binding to the target of interest (Geppert et al., 2010). What LBDD actually does is to build a model (so called, pharmacophore model) based on the knowledge of such molecules binding to the target and, in turn use this model for design of new drug candidates. Alternatively, LBDD can construct predictive, quantitative structure-activity relationship (QSAR). 
Pharmacophore modelling. Pharmacophore is an abstract description of minimum, steric and electronic features that are required for interaction of target protein with ligand(s). Inference of pharmacophore using knowledge on a set of ligands (training set) that can bind to the target is called pharmacophore modelling (Fig. 3A). The process in the development of pharmacophore model involves the alignment of multiple ligands (training set), which can determine the essential chemical features that are responsible for their bioactivity. The alignment of these multiple ligands can be achieved by superimposing a set of active molecules. Such superimposed molecules are then transformed into abstract representation of different features. Pharmacophore model explains why molecules of structural diversity can bind to the common sites and have the same biological effects
(Yang, 2010).

Ligand-based virtual screening (LBVS). Once pharmacophore model is built, then researchers can make prediction about whether candidate ligands are likely to bind to the target through comparison to the pharmacophore model. Such process is called ligand-based virtual screening (Fig. 2C). This approach is known to work best in scanning through candidate compounds with desired chemical features from a large, diverse set of chemical libraries (Oprea and Matter, 2004). In a way, LBVS works as a chemical database filters, and therefore can drastically reduce the number of chemical compounds for in vivo and in vitro studies.

A

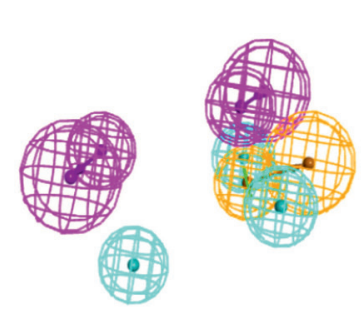

Pharmacophore generation

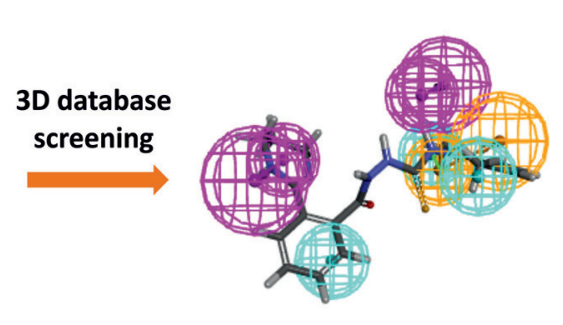

Compounds matching pharmacophore

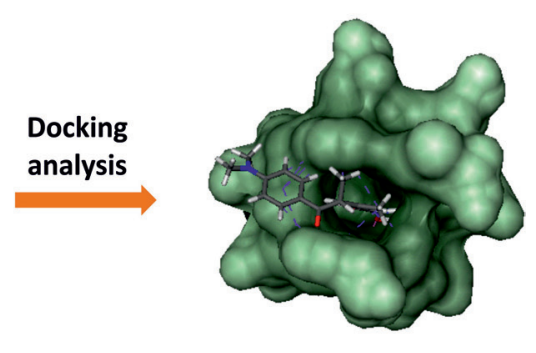

Docking interactions

B

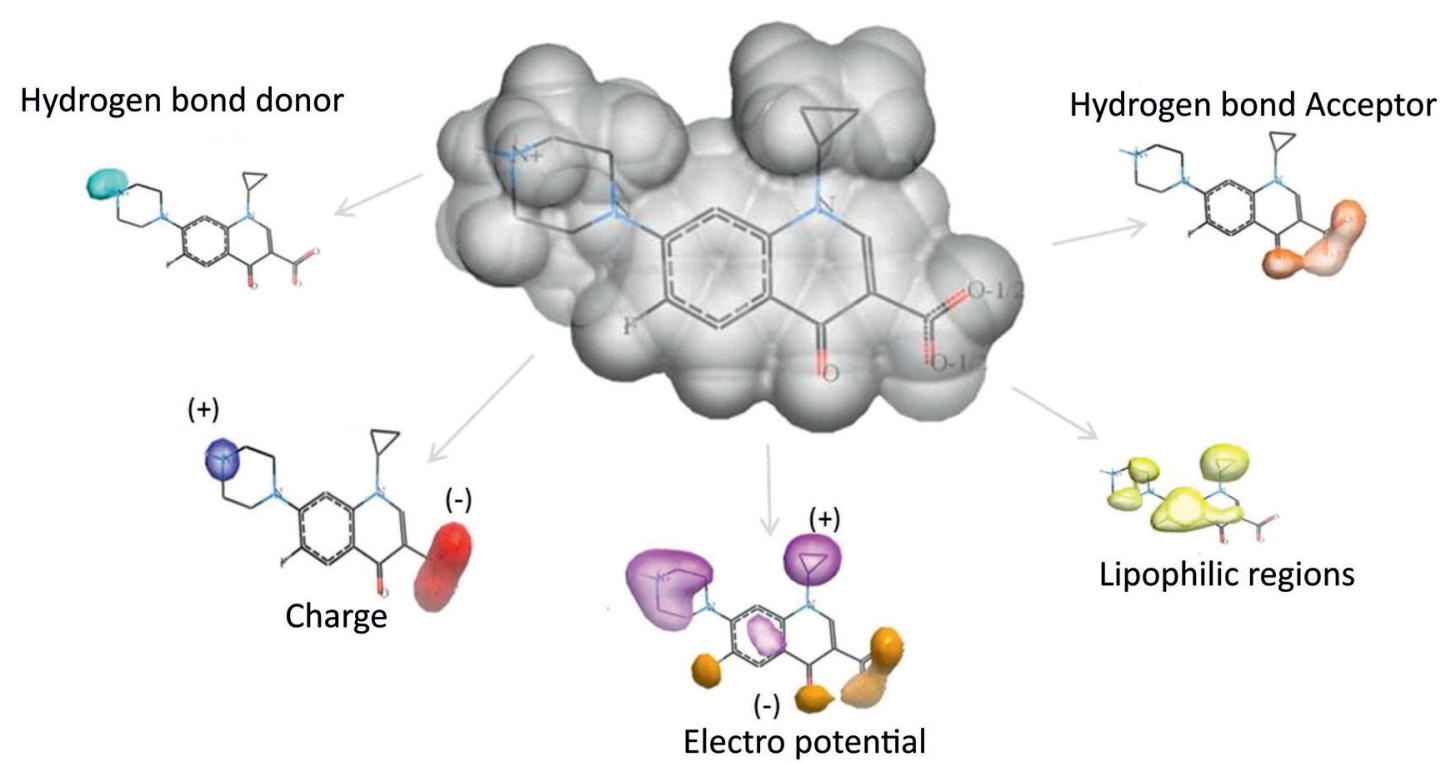

Fig. 3. The important steps of LBDD approach. (A) Pharmacophore designing and database screening. An example of pharmacophoric features: hydrogen bond donor, magenta; hydrophobic, cyan; ring aromatic, orange; the compound from Maybridge database matching the pharmacophoric features and the compound docking interactions. (B) Important molecular descriptors of QSAR that are vital in predicting the biological activity of compounds. 
Quantitative structure-activity relationship (QSAR). Hansch and Fujita introduced QSAR method based on the ground works of Hammett and Taft (Hansch and Fujita, 1964; Hansch, 1969). Quantitative structure-activity relationship (QSAR) models are regression or classification models used to predict activities of new chemical compounds based on their physico-chemical properties. In general, QSAR is a regression model where it relates a set of 'predictor' variables (X) such as physico-chemical properties and molecular descriptors to the potency of the 'response' variable (Y) such as biological activity of the compound. The QSAR summarizes the relationship of molecular descriptors (chemical structures) that describe the unique physico-chemical properties of compound sets of interest with their respective biological activity (Bordás et al., 2003; Goodford, 1985).Using this relationship, QSAR model is used to predict the activity of new compounds. The predictive ability of the QSAR model is dependent on the descriptors that were employed in the model generation (Fig. 3B).

de novo ligand design (DnLD). This method is generally known as fragment-based drug designing approach in which the novel ligand is built from the scratch using the creativity of the researchers to a very large extent. Owing to the advantage of tailoring the new compounds, DnLD has been effectively employed in both SBDD and LBDD approaches. In case of SBDD, the chemical features of active site in the target are considered to design the novel compounds, whereas in LBDD, the chemical features derived from pharmacophore or QSAR are used for novel compound design (Dey and Caflisch, 2008; Yang, 2010). However, the true behaviour of the chemical compound is in many cases uncertain and thus such lack of empirical evidence is a pitfall of this approach. The combinations of various modifications are made possible with the existence of chemical drawing tools, and the optimizations of the structure are performed with the energy minimization tools. Further, the knowledge on accurate modification that is essential for the ligand in the binding site can be revealed through docking programs (Böhm, 1996). The refinement of ligand molecules is generally an iterative process in which the emergence of optimal ligand with good binding stability and interactions results from convergence criteria.

\section{Drug Discovery - A Case Study}

In this section, we provide examples of CADD for plant pathogens. Below we demonstrate how candidate agrochemicals targeting a bacterial pathogen, Pseudomonas sy- ringae and a fungal pathogen, Colletotrichum gloeosporioides can be discovered using concepts and tools of CADD (Fig. 4).

Homology modelling and validation. For Pseudomonas syringae, through literature survey, we selected two enzymes, MurD and MurE ligases, which are involved in biosynthesis of bacterial peptidoglycan, as potential targets for rational drug designing approach (Bratkovič et al., 2008; Feil et al., 2005). For Colletotrichum gloeosporioides, the pelB gene encoding pectate lyase was selected as a target, since it is an important cell-wall-degrading enzyme for pathogenesis (Yakoby et al., 2000). Since the experimental 3D structures of these selected targets are unavailable in the PDB database, we employed theoretical protein modeling strategy. Using the homology modelling tool, Modeler9v9 (Eswar et al., 2006), the homology models of pectate lyase B protein sequence from C. gloeosporioides, and of MurD and MurE protein sequences from $P$. syringae were built by employing the target-template sequence alignment files (Fig. 4A). The X-ray crystal structures of cedar pollen allergen from Juniperus ashei (PDBID: 1pxz_A Chain) was used as potential template for modelling pectate lyase B protein from $C$. gloeosporioides. While the crystal structures of MurD (PDBID: 5a5f A chain) and MurE (PDBID: 1E8C_A chain) from E. coli are used as potential template from PDB database (Berman et al., 2000) for modelling the structures of MurD and MurE proteins from P. syringae. Among the generated models, one with the least RMSD (root-mean-square deviation of atomic positions: measure of the average distance between the atoms of superimposed proteins) value and final energy-minimized model was used for further analysis. The phi and psi angles representing the stereo-chemical parameters of the model (Fig. 4B), the compatibility of a generated 3D structure with its own amino acid sequence, and the regions of the modelled structure that can be rejected at the $95 \%$ and $99 \%$ confidence intervals were determined through PROCHECK (Laskowski et al., 1993), Verify3D (Eisenberg et al., 1997), and ERRAT (Colovos and Yeates, 1993), respectively, at SAVES structural analysis server (https://services.mbi.ucla. edu/SAVES/).

Candidate ligand selection (lead compounds) and virtual screening. Instead of scanning all available chemical databases, here we employed heuristic approach starting from compounds with known activity. Penicillin (anti-bacterial) and curcumin (anti-fungal) (Fig. 4C) are known inhibitors of MurD and MurE ligases and pectate lyase, respectively (Cho et al., 2006; Tomašić et al., 2012). Their structures 


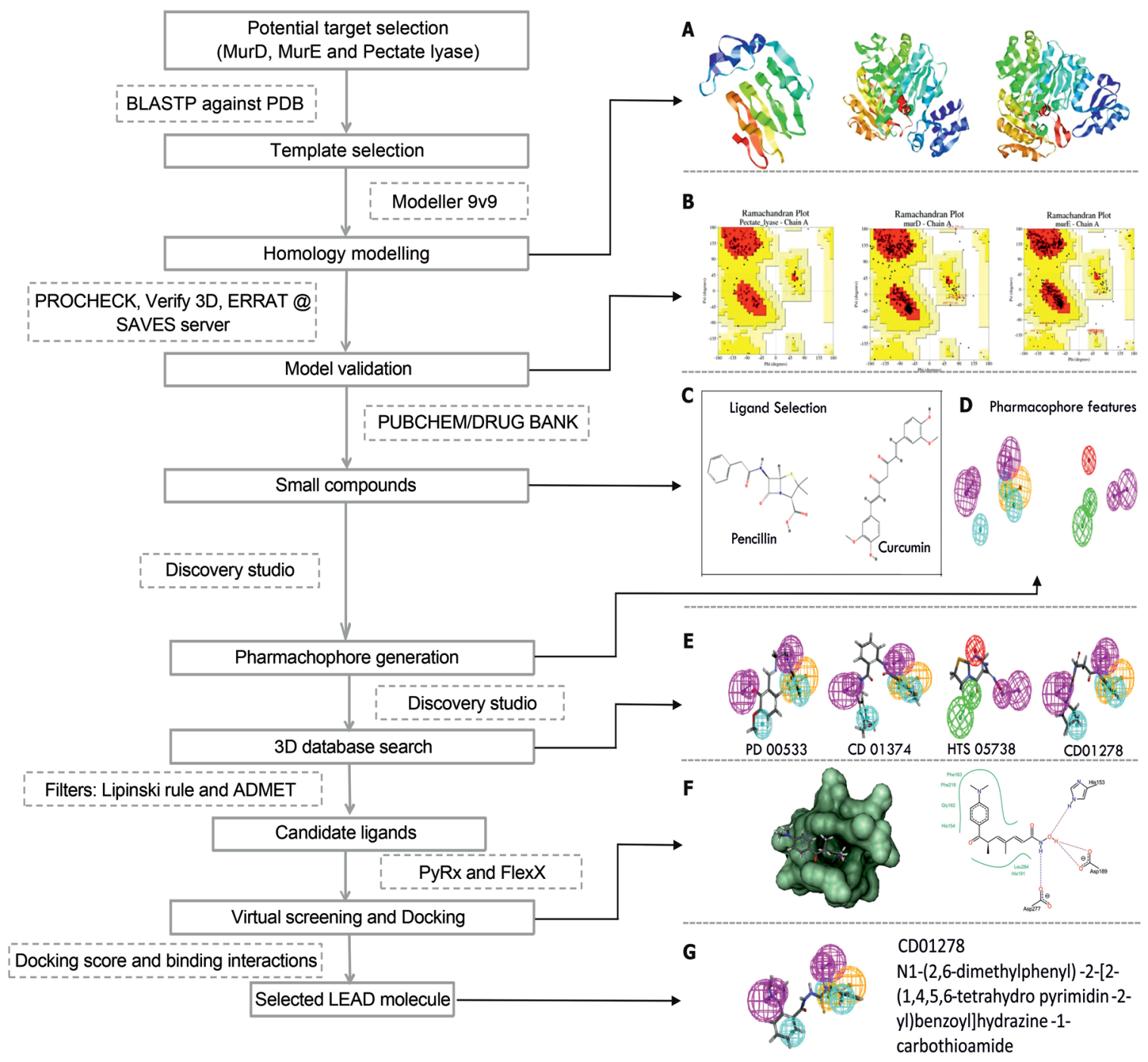

Fig. 4. The CADD protocol employed in the case study. Softwares, databases and servers used in the case study are given in dotted boxes, while the process is shown in solid boxes. (A) Homology models of pectate lyase, MurD and MurE (left to right). (B) Model validation using Ramachandran plot for each model. (C) Ligand selection (heuristic approach): structure of penicillin (anti-bacterial agent) and curcumin (anti-fungal agent) are shown. (D) Pharmacophore generation. Pharmacophoric features including hydrogen bond acceptor (green), hydrogen bond donor (magenta), hydrophobic (cyan), and ring aromatic (orange), ionizable positive charge (red) are shown here. (E) 3D database screening. Some of the compounds from Maybridge database matching the pharmacophore are shown. (F) Virtual screening and docking interactions. Docking interactions of Maybridge database compounds with the models are illustrated. (G) Identification of lead molecule: the compound showing best docking interaction with the modelled protein, CD01278 was selected.

were used to generate the various compounds modified with the combinations of halogen elements $(\mathrm{Br}, \mathrm{Cl}, \mathrm{F}$ and I) using ACD Chemsketch (Version 11, Advanced Chemistry Development, Inc., Toronto, ON, Canada, http://www. acdlabs.com/), resulting in 291 and 52 compounds that are similar in their structure to penicillin and curcumin, respectively. These new molecules were subjected to energy minimization by using CHARMm force field (Vanommeslaeghe et al., 2010) and collectively retrieved as 3D structures in SDF (structure data file) format for virtual screening against pectate lyase, MurD and MurE. Virtual screening of these 291 and 52 compounds by using FlexX module of LeadIT suite (Rarey et al., 1996) revealed their binding efficiencies through docking in the predicted binding pockets of modelled proteins. The compounds (2S,5R,6R)-3,3dimethyl-7-oxo-6-[(2-pyridin-4-ylacetyl)amino]-4-thia-1azabicyclo [3.2.0] heptane-2-carboxylic acid (hereafter compound-1) similar to penicillin and (1E,6E)-1,7-bis(3,4dihydroxy-5-methoxyphenyl)hepta-1,6-diene-3,5-dione (hereafter compound-2) similar to curcumin with the best 
docking score (binding energy) were used for the pharmacophore modelling. Note that here we have employed both SBDD and LBDD approaches.

Pharmacophore modelling and database screening. The pharmachophore model was generated against the compound- 1 and compound- 2 by using auto pharmachophore generation option in Discovery Studio 2.5 (Accelrys Software Inc., San Diego, USA), which considers the chemical feature types and resulted ten pharmachophore models (hypotheses). The best pharmachophore model was selected based on the high correlation coefficient and lower RMSD (Fig. 4D). The Search 3D Database protocol with default search option implemented in Discovery studio was used for screening against Maybridge database (http://www. maybridge.com/) with various filters such as estimated activity and Lipinski's rule of five ( $\leq 5$ hydrogen bond donors; $\leq 10$ hydrogen bond acceptors; molecular mass $<500$ dal and $\log \mathrm{P}$ (octanol-water partition coefficient) $<5$ ) (Lipinski et al., 1997). The final hit compounds from Maybridge database having good fit scores ( $>3$ ) for the compound-1 pharmacophore are PD00533, CD01374, CD04888 and CD01278. While the final hit compounds for compound-2 pharmacophore are CD01278, S10124, HTS05738 and BTB01629 (Fig. 4E) (The IUPAC name of these compounds are given in Supplementary Table 1). These compounds are further used for docking studies against the modelled proteins and found that the compound CD01278 (Fig. 4G) exhibited better binding energies with the three protein models, which significantly implies that this compound might serve as potential lead molecule to control the disease caused by both the $P$. syringae and $C$. gloeosporioides.

\section{Success and Limitations of CADD}

The advent of robust technologies in the computational methods such as combinatorial chemistry and highthroughput screening methods has accelerated the modern drug discovery process to screen large number of chemical compounds, compared to the conventional drug designing process that is time-taking, laborious and costly (trial and error), and has high risk of failure (Talele et al., 2010). These in silico methods opened the possibility of synthesizing and/or testing novel compounds as drugs. Moreover, the optimization process of lead chemical compounds has allowed medicinal chemists to synthesize the novel compounds with reduced risk of toxicity. Although the conventional methods can successfully yield candidate compounds, the high molecular weight, lipophilicity, toxic- ity, low absorption, distribution, metabolism excretion and non-specific binding may result in negative consequences in clinical trials. In this aspect, CADD is highly effective, since predictive power of CADD facilitates selection of more promising lead candidates by minimizing time being wasted on dead end compounds.

Despite all these advantages of CADD, its limitations should be noted. Most prominently, accurate simulation of complexity that biological systems have is not possible even with state of art techniques and high computational power. Such limitation is the biggest challenge in CADD and pertains to uncertainties associated with high flexibility of target, conformational changes of proteins, and scarce of experimental data for absorption, distribution, metabolism, and toxicity of compounds (Baig et al., 2016; Singh, 2014).

\section{Conclusion}

CADD combines knowledges from diverse disciplines such as chemo-informatics, and genomics with computational algorithms and technologies to enable discovery of new knowledge - discovery/development of new drugs. In this review, we outlined key concepts of CADD and provided application of CADD to discovery/development of potential lead agrochemicals targeting proteins from plant pathogens. Considering current pace at which virulence/ pathogenicity factors are uncovered with aid of genomics, CADD will be playing important roles in narrowing widening gaps between our understanding of pathogenesis mechanisms at the molecular level and translation of such knowledge into development of disease control measures and management strategies.

One of the barriers for CADD in gaining considerable momentum in areas other than pharmaceutical industry is probably accessibility of CADD to researchers from other disciplines. Despite increasing efforts, many of CADD tools still lack user-friendly interface, and configuration of overwhelming number of parameters is a daunting task. Therefore, successful use of those tools naturally requires a great deal of expertise. Fortunately, recent design of CADD tools is putting more emphasis on creating tools and algorithms that are accessible to wider range of researchers. Furthermore, it should be noted that there are no fundamentally better techniques, even though wide variety of computational tools are used. From these perspectives, we would like to strongly encourage researchers in molecular plant pathology to adopt these robust technologies in order to combat important crop diseases, using our review as a guide. Tools and strategies that we have used for $P$. $s y$ ringae and $C$. gloeosporioides will be a good starting point 
toward that end.

\section{Acknowledgments}

We wish to thank Dr. A. Syed Mohammed, Department of Chemistry, Sadakathullah Appa College, Tirunelveli, India for supporting the pharmacophore modelling and 3D database screening with their software facilities (Discovery studio V2.5). This work was supported by 2017 Yeungnam University Research Grant.

\section{References}

Adam, M. 2005. Integrating research and development: the emergence of rational drug design in the pharmaceutical industry. Stud. Hist. Philos. Biol. Biomed. Sci. 36:513-537.

Al-Hussaini, R. and Mahasneh, A. M. 2009. Microbial growth and quorum sensing antagonist activities of herbal plants extracts. Molecules 14:3425-3435.

Baig, M. H., Ahmad, K., Roy, S., Ashraf, J. M., Adil, M., Siddiqui, M. H., Khan, S., Kamal, M. A., Provazník, I. and Choi, I. 2016. Computer aided drug design: success and limitations. Curr. Pharm. Des. 22:572-81.

Berman, H. M., Westbrook, J., Feng, Z., Gilliland, G., Bhat, T. N., Weissig, H., Shindyalov, I. N. and Bourne, P. E. 2000. The protein data bank. Nucleic Acids Res. 28:235-242.

Boch, J. and Bonas, U. 2010. Xanthomonas AvrBs3 family-type III effectors: discovery and function. Annu. Rev. Phytopathol. 48:419-436.

Bocsanczy, A. M., Nissinen, R. M., Oh, C.-S. and Beer, S. V. 2008. HrpN of Erwinia amylovora functions in the translocation of DspA/E into plant cells. Mol. Plant Pathol. 9:425-434.

Böhm, H. J. 1996. Current computational tools for de novo ligand design. Curr. Opin. Biotechnol. 7:433-436.

Bordás, B., Kömíves, T. and Lopata, A. 2003. Ligand-based computer-aided pesticide design. A review of applications of the CoMFA and CoMSIA methodologies. Pest Manag. Sci. 59:393-400.

Boucher, C. A., Barberis, P. A. and Demery, D. A. 1985. Transposon mutagenesis of Pseudomonas solanacearum: isolation of Tn5-induced avirulent mutants. Microbiology 131:24492457.

Boyd, L. A., Ridout, C., O’Sullivan, D. M., Leach, J. E. and Leung, H. 2013. Plant-pathogen interactions: disease resistance in modern agriculture. Trends Genet. 29:233-240.

Bratkovič, T., Lunder, M., Urleb, U. and Štrukelj, B. 2008. Peptide inhibitors of MurD and MurE, essential enzymes of bacterial cell wall biosynthesis. J. Basic Microbiol. 48:202-206.

Cairns, T. C., Studholme, D. J., Talbot, N. J. and Haynes, K. 2016. New and improved techniques for the study of pathogenic fungi. Trends Microbiol. 24:35-50.

Cavasotto, C. N. and Phatak, S. S. 2009. Homology modeling in drug discovery: current trends and applications. Drug Discov.
Today 14:676-683.

Chandler, D., Bailey, A. S., Tatchell, G. M., Davidson, G., Greaves, J. and Grant, W. P. 2011. The development, regulation and use of biopesticides for integrated pest management. Philos. Trans. R. Soc. Lond., B, Biol. Sci. 366:1987-1998.

Chandra, N. 2011. Computational approaches for drug target identification in pathogenic diseases. Expert. Opin. Drug Disc. 6:975-979.

Chen, C. and Dickman, M. B. 2004. Dominant active Rac and dominant negative Rac revert the dominant active Ras phenotype in Colletotrichum trifolii by distinct signalling pathways. Mol. Microbiol. 51:1493-1507.

Cho, J. Y., Choi, G. J., Lee, S. W., Jang, K. S., Lim, H. K., Lim, C. H., Lee, S. O., Cho, K. Y. and Kim, J. C. 2006. Antifungal activity against Colletotrichum spp. of curcuminoids isolated from Curcuma longa L. rhizomes. J. Microbiol. Biotechnol. 16:280-285.

Colovos, C. and Yeates, T. O. 1993. Verification of protein structures: patterns of nonbonded atomic interactions. Protein Sci. 2:1511-1519.

Cos, P., Vlietinck, A. J., Berghe, D. V. and Maes, L. 2006. Antiinfective potential of natural products: how to develop a stronger in vitro 'proof-of-concept'. J. Ethnopharmacol. 106:290-302.

Dean, R., Van Kan, J. A., Pretorius, Z. A., Hammond-Kosack, K. E., Di Pietro, A., Spanu, P. D., Rudd, J. J., Dickman, M., Kahmann, R., Ellis, J. and Foster, G. D. 2012. The Top 10 fungal pathogens in molecular plant pathology. Mol. Plant Pathol. 13:414-430.

Dehury, B., Sahu, M., Sarma, K., Sahu, J., Sen, P., Modi, M. K., Sharma, G. D., Choudhury, M. D. and Barooah, M. 2013. Molecular phylogeny, homology modeling, and molecular dynamics simulation of race-specific bacterial blight disease resistance protein (xa5) of rice: a comparative agriproteomics approach. OMICS 17:423-438.

Deslandes, L. and Rivas, S. 2012. Catch me if you can: bacterial effectors and plant targets. Trends Plant Sci. 17:644-655.

Dey, F. and Caflisch, A. 2008. Fragment-based de novo ligand design by multiobjective evolutionary optimization. J. Chem. Inf. Model 48:679-690.

Doucet-Personeni, C., Bentley, P. D., Fletcher, R. J., Kinkaid, A., Kryger, G., Pirard, B., Taylor, A., Taylor, R., Taylor, J., Viner, R., Silman, I., Sussman, J. L., Greenblatt, H. M. and Lewis, T. 2001. A structure-based design approach to the development of novel, reversible AChE inhibitors. J. Med. Chem. 44:32033215.

Duffy, B. C., Zhu, L., Decornez, H. and Kitchen, D. B. 2012. Early phase drug discovery: cheminformatics and computational techniques in identifying lead series. Bioorg. Med. Chem. 20:5324-5342.

Dunn, M. F., Ramirez-Trujillo, J. A. and Hernández-Lucas, I. 2009. Major roles of isocitrate lyase and malate synthase in bacterial and fungal pathogenesis. Microbiology 155:31663175 . 
Durrant, D. J. and McCammon, J. A. 2010. Computer-aided drugdiscovery techniques that account for receptor flexibility. Curr. Opin. Pharmacol. 10:770-774.

Eisenberg, D., Lüthy, R. and Bowie, J. U. 1997. VERIFY3D: assessment of protein models with three-dimensional profiles. Methods Enzymol. 277:396-406.

El Zoeiby, A., Sanschagrin, F. and Levesque, R. C. 2003. Structure and function of the Mur enzymes: development of novel inhibitors. Mol. Microbiol. 47:1-12.

Eswar, N., Webb, B., Marti-Renom, M. A., Madhusudhan, M. S., Eramian, D., Shen, M., Pieper, U. and Sali, A. 2006. Comparative protein structure modeling using modeller. Curr. Protoc. Bioinformatics Chapter 5:Unit-5.6.

Feil, H., Feil, W. S., Chain, P., Larimer, F., DiBartolo, G., Copeland, A., Lykidis, A., Trong, S., Nolan, M., Goltsman, E., Thiel, J., Malfatti, S., Loper, J. E., Lapidus, A., Detter, J. C., Land, M., Richardson, P. M., Kyrpides, N. C., Ivanova, N. and Lindow, S. E. 2005. Comparison of the complete genome sequences of Pseudomonas syringae pv. syringae B728a and pv. tomato DC3000. Proc. Natl. Acad. Sci. U.S.A. 102:1106411069.

Ferreira, L. G., Dos Santos, R. N., Oliva, G. and Andricopulo, A. D. 2015. Molecular docking and structure-based drug design strategies. Molecules 20:13384-13421.

Franceschetti, M., Maqbool, A., Jiménez-Dalmaroni, M. J., Pennington, H. G., Kamoun, S. and Banfield, M. J. 2017. Effectors of filamentous plant pathogens: commonalities amid diversity. Microbiol. Mol. Biol. Rev. 81:e0066-16.

Gao, Y. M., Wang, X. J., Zhang, J., Li, M., Liu, C. X., An, J., Jiang, L. and Xiang, W. S. 2012. Borrelidin, a potent antifungal agent: insight into the antifungal mechanism against Phytophthora sojae. J. Agric. Food Chem. 60:9874-9881.

Geppert, H., Vogt, M. and Bajorath, J. 2010. Current trends in ligand-based virtual screening: molecular representations, data mining methods, new application areas, and performance evaluation. J. Chem. Inf. Model 50:205-216.

Goodford, P. J. 1985. A computational procedure for determining energetically favorable binding sites on biologically important macromolecules. J. Med. Chem. 28:849-857.

Han, R., Zhang, J., Li, S., Cao, S., Geng, H., Yuan, Y., Xiao, W., Liu, S. and Liu, D. 2010. Homology modeling and screening of new $14 \alpha$-demethylase inhibitor (DMI) fungicides based on optimized expression of CYP51 from Ustilago maydis in Escherichia coli. J. Agric. Food Chem. 58:12810-12816.

Hanessian, S., Lu, P. P., Sancéau, J. Y., Chemla, P., Gohda, K., Fonne-Pfister, R., Prade, L. and Cowan-Jacob, S. W. 1999. An enzyme-bound bisubstrate hybrid inhibitor of adenylosuccinate synthetase. Angew. Chem. Int. Ed. 38:3159-3162.

Hansch, C. 1969. A quantitative approach to biochemical structure-activity relationships. Acc. Chem. Res. 2:232-239.

Hansch, C. and Fujita, T. 1964. $p-\sigma-\pi$ Analysis. A method for the correlation of biological activity and chemical structure. $J$. Am. Chem. Soc. 86:1616-1626.

Hentschel, U., Steinert, M. and Hacker, J. 2000. Common mo- lecular mechanisms of symbiosis and pathogenesis. Trends Microbiol. 8:226-231.

Herron, S. R., Benen, J. A., Scavetta, R. D., Visser, J. and Jurnak, F. 2000. Structure and function of pectic enzymes: virulence factors of plant pathogens. Proc. Natl. Acad. Sci. U.S.A. 97:8762-8769.

Huang, S. Y. and Zou, X. 2010. Advances and challenges in protein-ligand docking. Int. J. Mol. Sci. 11:3016-3034.

Hughes, J. P., Rees, S. S., Kalindjian, S. B. and Philpott, K. L. 2011. Principles of early drug discovery. Br. J. Pharmacol. 162:1239-1249.

Imam, J., Singh, P. K. and Shukla, P. 2016. Plant microbe interactions in post genomic era: perspectives and applications. Front. Microbiol. 7:1488.

Jain, V., Sharma, A., Singh, G., Yogavel, M. and Sharma, A. 2017. Structure-based targeting of orthologous pathogen proteins accelerates antiparasitic drug discovery. ACS Infect. Dis. 3:281-292.

Jovanovic, M., James, E. H., Burrows, P. C., Rego, F. G., Buck, M. and Schumacher, J. 2011. Regulation of the co-evolved HrpR and HrpS AAA+ proteins required for Pseudomonas syringae pathogenicity. Nat. Commun. 2:177.

Kalyaanamoorthy, S. and Chen, Y. P. P. 2011. Structure-based drug design to augment hit discovery. Drug Discov. Today 16:831-839.

Kandakatla, N. and Ramakrishnan, G. 2014. Ligand based pharmacophore modeling and virtual screening studies to design novel HDAC2 inhibitors. Adv. Bioinformatics 2014:812148.

Kapetanovic, I. M. 2008. Computer-aided drug discovery and development (CADDD): in silico-chemico-biological approach. Chem. Biol. Interact. 171:165-176.

Katiyar, C., Gupta, A., Kanjilal, S. and Katiya, S. 2012. Drug discovery from plant sources: an integrated approach. Ayu 33:10-19.

Laskowski, R. A., MacArthur, M. W., Moss, D. S. and Thornton, J. M. 1993. PROCHECK: a program to check the stereochemical quality of protein structures. J. Appl. Cryst. 26:283-291.

Lipinski, C. A., Lombardo, F., Dominy, B. W. and Feeney, P. J. 1997. Experimental and computational approaches to estimate solubility and permeability in drug discovery and development settings. Adv. Drug Deliv. Rev. 23:3-25.

Liu, L., Qu, J., Li, D., Long, G. and Deng, Z. 2012. In silico characterization and molecular modeling of GntR family regulators in Xanthomonas axonopodis pv. citri: Implications for primary metabolism or virulence. Plant Omics 5:494-502.

Mansfield, J., Genin, S., Magori, S., Citovsky, V., Sriariyanum, M., Ronald, P., Dow, M. A. X., Verdier, V., Beer, S. V., Machado, M. A., Toth, I. A. N., Salmond, G. and Foster, G. D. 2012. Top 10 plant pathogenic bacteria in molecular plant pathology. Mol. Plant. Pathol. 13:614-629.

McInnes, C. 2007. Virtual screening strategies in drug discovery. Curr. Opin. Chem. Biol. 11:494-502.

Mole, B. M., Baltrus, D. A., Dangl, J. L. and Grant, S. R. 2007. Global virulence regulation networks in phytopathogenic 
bacteria. Trends Microbiol. 15:363-371.

Oprea, T. I. and Matter, H. 2004. Integrating virtual screening in lead discovery. Curr. Opin. Chem. Biol. 8:349-358.

Pathak, R. K., Taj, G., Pandey, D., Kasana, V. K., Baunthiyal, M. and Kumar, A. 2016. Molecular modeling and docking studies of phytoalexin(s) with pathogenic protein(s) as molecular targets for designing the derivatives with anti-fungal action on 'Alternaria' spp. of 'Brassica'. Plant Omics 9:172-182.

Pitzschke, A. and Hirt, H. 2010. New insights into an old story: Agrobacterium-induced tumour formation in plants by plant transformation. EMBO J. 29:1021-1032.

Ramakrishnan, J., Rathore, S. S. and Raman, T. 2016. Review on fungal enzyme inhibitors-potential drug targets to manage human fungal infections. RSC Adv. 6:42387-42401.

Rarey, M., Kramer, B., Lengauer, T. and Klebe, G. 1996. A fast flexible docking method using an incremental construction algorithm. J. Mol. Biol. 261:470-489.

Rost, B. 1999. Twilight zone of protein sequence alignments. Protein Eng. 12:85-94.

Rost, B. and Sander, C. 1996. Bridging the protein sequencestructure gap by structure predictions. Annu. Rev. Biophys. Biomol. Struct. 25:113-136.

Sagatova, A. A., Keniya, M. V., Wilson, R. K., Monk, B. C. and Tyndall, J. D. 2015. Structural insights into binding of the antifungal drug fluconazole to Saccharomyces cerevisiae lanosterol 14 $\alpha$-demethylase. Antimicrob. Agents Chemother. 59:4982-4989.

Schwede, T. 2013. Protein modeling: What happened to the "protein structure gap"? Structure 21:1531-1540.

Siegel, M. R. 1981. Sterol-inhibiting fungicides: effects on sterol biosynthesis and sites of action. Plant Dis. 65:986-989.

Singh, D. B. 2014. Success, limitation and future of computer aided drug designing. Transl. Med. (Sunnyvale) 4:e127.

Sliwoski, G., Kothiwale, S., Meiler, J. and Lowe, E. W. 2013. Computational methods in drug discovery. Pharmacol. Rev. 66:334-395.

Soundararajan, P., Sakkiah, S., Sivanesan, I., Lee, K. W. and Jeong, B. R. 2011. Macromolecular docking simulation to identify binding site of FGB1 for antifungal compounds. Bull. Korean Chem. Soc. 32:3675-3681.

Strange, R. N. and Scott, P. R. 2005. Plant disease: a threat to global food security. Annu. Rev. Phytopathol. 43:83-116.

Takano, Y., Kikuchi, T., Kubo, Y., Hamer, J. E., Mise, K. and Furusawa, I. 2000. The Colletotrichum lagenarium MAP kinase gene CMK1 regulates diverse aspects of fungal pathogenesis. Mol. Plant-Microbe Interact. 13:374-383.
Talele, T. T., Khedkar, S. A. and Rigby, A. C. 2010. Successful applications of computer aided drug discovery: moving drugs from concept to the clinic. Curr. Top. Med. Chem. 10:127141.

Taylor, D. 2015. the pharmaceutical industry and the future of drug development. In: Pharmaceuticals in the environment, eds. by R. E. Hester and R. M. Harrison, pp. 1-33. The Royal Society of Chemistry, London.

Tomašić, T., Sink, R., Zidar, N., Fic, A., Contreras-Martel, C., Dessen, A., Patin, D., Blanot, D., Müller-Premru, M., Gobec, S., Zega, A., Kikelj, D. and Mašič, L. P. 2012. Dual inhibitor of MurD and MurE ligases from Escherichia coli and Staphylococcus aureus. ACS Med. Chem. Lett. 3:626-630.

Vanommeslaeghe, K., Hatcher, E., Acharya, C., Kundu, S., Zhong, S., Shim, J., Darian, E., Guvench, O., Lopes, P., Vorobyov, I. and Mackerell, A. D. 2010. CHARMM general force field: a force field for drug-like molecules compatible with the CHARMM all-atom additive biological force fields. J. Comput. Chem. 31:671-690.

Walter, M. W. 2002. Structure-based design of agrochemicals. Nat. Prod. Rep. 19:278-291.

Weigelt, J. 2010. Structural genomics-impact on biomedicine and drug discovery. Exp. Cell Res. 316:1332-1338.

Wride, D. A., Pourmand, N., Bray, W. M., Kosarchuk, J. J., Nisam, S. C., Quan, T. K., Berkeley, R. F., Katzman, S., Hartzog, G. A., Dobkin, C. E. and Lokey, R. S. 2014. Confirmation of the cellular targets of benomyl and rapamycin using next-generation sequencing of resistant mutants in $S$. cerevisiae. Mol. Biosyst. 10:3179-3187.

Xue, Y., Shui, G. and Wenk, M. R. 2014. TPS1 drug design for rice blast disease in Magnaporthe oryzae. Springerplus 3:18.

Yakoby, N., Kobiler, I., Dinoor, A. and Prusky, D. 2000. pH regulation of pectate lyase secretion modulates the attack of $\mathrm{Col}$ letotrichum gloeosporioides on avocado fruits. Appl. Environ. Microbiol. 66:1026-1030.

Yang, G. F., Jiang, X. H., Ding, Y. and Yang, H. Z. 2002. Three dimentional quantitative structure-activity relationships of novel 2-heteroaryl-4-chromanone derivatives. Acta Chim. Sin. 60:134-138.

Yang, S. Y. 2010. Pharmacophore modeling and applications in drug discovery: challenges and recent advances. Drug Discov. Today 15:444-450.

Zhou, Y., Chen, L., Hu, J., Duan, H., Lin, D., Liu, P., Meng, Q., Li, B., Si, N., Liu, C. and Liu, X. 2015. Resistance mechanisms and molecular docking studies of four novel QoI fungicides in Peronophythora litchii. Sci. Rep. 5:17466. 